\title{
Diagnosis And Outcome Of Psychiatric Referrals To The Field Mental Health Team, 202 Field Hospital, Op Telic I
}

\author{
JN Scott
}

\begin{abstract}
Objectives

To assess referrals to a Field Hospital Mental Health Team (FMHT), assign a diagnosis, provide appropriate treatment, and decide whether suitable for safe return to unit in theatre (RTU), or evacuation home on psychiatric grounds (evac).
\end{abstract}

\section{Methods}

All documented referrals to the FMHT of 202 Field Hospital during the Op Telic 1 study period of $17 \mathrm{March}$ (day 1) to 23 July 2003 (day 129) were included. Data were collected on rank, gender, diagnosis, outcome (whether RTU or evac), and whether TA before mobilisation. Diagnosis was assigned by ICD10 criteria.

\section{Results}

The FMHT documented 170 cases, 12 of whom were seen twice and one on three occasions, resulting in 184 referrals, all of whom were British. The commonest diagnosis was adjustment reaction (F43), accounting for $68 \%$ of all cases $(n=116)$. These were divided between chiefly theatre-related $(n=77)$ or chiefly home-related $(n=39)$ reactions. The majority (94\%) of these cases were RTU. Referrals where the diagnosis was a Depressive disorder $(\mathrm{F} 32, \mathrm{n}=23)$ or Intentional self-harm (by sharp object, $\mathbf{X} 78, \mathbf{n}=7$ ) were evacuated. Outcome was similar for Regular and TA personnel, with on average $72 \%$ of cases RTU. The majority of cases seen were ORs, reflecting their numbers in theatre. Only 14 NCOs and 14 officers were referred. Thirteen of the latter were TA before mobilisation. Gender was not associated with outcome, or TA status, but was associated with rank, in that significantly more female officers were referred. The FMHT role tasks emerged as (a) psychiatric triage and treatment, (b) psychological support of hospital staff, and (c) welfare and pastoral care liaison.

JN Scott TD FRCP MRCPsych 204 (NI) Fd Hosp (V), BFPO 801
The utility of the psychiatric management model employed, built upon previous military medical doctrines, was tested in a modern theatre of conflict, and seemed to prove its worth.

"Any psychiatrist finding it easier to send a frightened young soldier who reminds one of one's own self, or one's own son, to the rear, than to return him to combat duty, should realise that medically to evacuate a patient who has not yet performed with the degree of honour required of him (by both himself and his community) is the greatest possible psychiatric mishandling, and the greatest possible unkindness... The psychiatrist should be immersed in front line realities from the start, so that they can understand the needs of the Army as a whole, and not 'over-identify' with individual patients... the psychiatrist (loses) anxiety and guilt when making decisions, because he (becomes) convinced that it is in the best interests of the individual to rejoin his combat unit, for in no other way can the individual regain confidence and mastery of the situation, and prevent chronic tension and guilt." Glass, 1954, 1955 (1)

\section{Introduction}

Military Psychiatry practice currently entails in-theatre forward treatment in specialist units. By this means, maximal opportunity is provided to ensure that thorough early assessment occurs, so that those with shortlived mental reactions can receive the rapid recognition, support, rest, and rehabilitation (physical and emotional) that they need, and thus be returned to duty in theatre. Such an outcome both meets military reinforcement aims, and also enhances and restores the individual's sense of personal control and 'mastery of the situation...' (1).

This doctrine is based upon hard-won and often bitter documented experience from previous conflicts, essentially from 1914 onwards. Such history is comprehensively depicted (2).

The 'PIES' approach is applied; that is, Proximity (being treated close to the location of trauma, with minimal evacuation); Immediacy (being treated as soon after the trauma as possible); Expectancy (the clear expectation of all concerned that return to unit in theatre will be the outcome in the vast majority of cases); and Simplicity (desirable in the chaos of war). Now widely promulgated following the results from Israeli studies (3), this concept was introduced by Salmon (4) who created a psychiatric service in the medical corps of the 
United States Army in the First World War, and was further developed by Glass (1), in the Mediterranean in 1943, and Korea in 1951. These principles were for the most part followed in the period of the present study, and they underpin the approach adopted, especially after week 3 .

\section{Field Hospital}

A TA unit, 202 served in Op Telic I from mid March to late July 2003. 202 took over from 33 Field Hospital at Camp Coyote, North Kuwait, and psychiatric casualties were received from 17 March (day 1 of study period; day 1 of hostilities was $20 \mathrm{March}$ ). 202 closed at Coyote on 6 May (day 51), and the unit moved north and took over ('relief in place') from 34 Field Hospital at Shaibah airfield, Basra, Iraq on 16 May (day 61) until handover to 33 Field Hospital on 23 July (day 129). A new tented hospital was built during this period by 69 Gurkha Fd Sqn (QGE), assisted by elements from 202, and was officially opened by Major General Peter Wall CBE as 'BMH Shaibah' on 28 June. Clinical activity continued without interruption throughout, and the step-wise move from old to new, in mid June, caused no hiatus in service.

The Psychiatry department was staffed by the FMHT, and occupied tented accommodation whose location in the various hospital sites changed about five times, as operational requirements dictated. The chief requisite was privacy. Another was closeness to the Padre's dept, and also Welfare, to allow easy liaison.

There were no in patient psychiatric beds. Referrals requiring overnight stay for whatever reason were bedded-down in one of the general wards. Referrals initiated, and were accepted, from a range of sources, but all were at some stage channelled through an MO, with whom contact was made as closely as theatre conditions permitted. It is estimated that 202 received at least $80 \%$ of total British psychiatric casualties in theatre during the study period (5). The FMHT also provided a full liaison psychiatry service to other wards and departments of 202.

\section{Field Mental Health Team (FMHT)} Staffing Cover

At Camp Coyote available nursing manpower allowed a 24-hour rota, so that at least two Psychiatric Nurses were on duty at all times. Equally one Consultant Psychiatrist was on duty, or available on-call. There was no community mental health $(\mathrm{CMH})$ outreach service at this stage. This was available to forward elements of the force from embedded CMH teams, separate from 202, who provided briefings on stress topics, support and advice to commanders, and also patient consultation as requested. It was not thought that additional outreach would have been an efficient use of 202 resources. Nor was any unmet outreach psychiatric need perceived, nor brought to attention.

At Shaibah there was an 0800 to 2000 rota, with on-call cover thereafter. A Consultant Psychiatrist was also on duty, or available on-call. FMHT staff provided on request various briefings to local units, some 12 sessions in all. An 'outreach' service was available, and was requested and provided on one occasion, after a shooting tragedy on 24 June.

\section{Methods}

Records were kept of all referrals to the FMHT during Op Telic 1. Data collected included details of rank, gender, diagnosis, outcome (whether RTU or evac), and whether TA before mobilisation. Further demographic data was either not available or was not consistently collected in the circumstances which prevailed.

Referral Policy. A policy of 'open' and 'self' referral was encouraged, by which FMHT members had many 'informal' approaches made to them, directly and indirectly, from hospital staff colleagues and others. These usually involved concerns about psychological aspects of patient care. It was decided at the outset to encourage these, on as confidential a basis as the person requested, and without them being formally registered, or indeed any permanent notes kept. However, it was agreed that if such referrals seemed serious in nature, or a person repeatedly referred, then they would be registered as a hospital 'case', and documented. The therapeutic presence or 'footprint' of the FMHT thus extended far beyond the 184 referral episodes whose analysis comprises the present study.

Treatment Philosophy. If a person was dysfunctional in their role, with a degree of risk to self or others causing concern to senior command, due to incapacitating mental disorder not likely to be quickly treated in theatre, or such attempted treatment having been unsuccessful, they were deemed to require medical evacuation to a UK psychiatric facility for further evaluation. GP review was also advised in the case of TA personnel.

Given its 'finality' (no case evacuated later returned to theatre within the study period, ending 22 July 2003), this assessment was arrived at only after careful consideration, indeed with some reluctance, and usually only after the casualty having one or more nights' bedding-down and sleep $(1,3)$.

Short of this, the aim was to resolve the issue causing distress to the individual through well-established principles of brief psychotherapy and casework, including rest, respite, sleep, ventilation, and focussed reassurance and explanation. By such means most concerns were quelled, building upon the person's usually-present own sense of duty, especially to comrades and unit, 
Table 1. Diagnoses and outcome for all psychiatric cases.

\begin{tabular}{|l|c|c|c|c|}
\hline Diagnosis & ICD & Number (\%) & \multicolumn{2}{|c|}{$\begin{array}{c}\text { Number based on final referral } \\
\text { Evac }\end{array}$} \\
\hline $\begin{array}{l}\text { Adjustment reaction } \\
\text { (mostly theatre-related) }\end{array}$ & F43(t) & $77(45.3)$ & 73 & 4 \\
\hline $\begin{array}{l}\text { Adjustment reaction } \\
\text { (mostly home-related) }\end{array}$ & F43(h) & $39(22.9)$ & 36 & 3 \\
\hline Depressive episode & F32 & $23(13.5)$ & 0 & 23 \\
\hline Somatoform disorder & F45 & $8(4.7)$ & 8 & 0 \\
\hline ISH (sharp object) & X78 & $7(4.1)$ & 0 & 7 \\
\hline General anxiety disorder & F41.1 & $5(2.9)$ & 1 & 4 \\
\hline Harmful alcohol use & F10.1 & $3(1.8)$ & 1 & 2 \\
\hline NBC phobia & F40.2 & $2(1.2)$ & 1 & 1 \\
\hline Delirium (heat exhaustion) & F05 & $2(1.2)$ & 2 & 0 \\
\hline ?PTSD flashback & F43.1 & $2(1.2)$ & 1 & 1 \\
\hline Dissociative disorder & F44 & $1(0.6)$ & 0 & 1 \\
\hline Hypomanic episode & F30 & $1(0.6)$ & 0 & 47 \\
\hline TOTAL & & 170 & 123 & \\
\hline
\end{tabular}

${ }^{\star} R T U=$ Returned to Unit in theatre ${ }^{\star}{ }^{\star}$ Evac $=$ Evacuated home, usually to UK

motivation to master and overcome, and resolve to see the matter through.

ICD-10 Diagnoses. Given its universality of application and acceptance as 'common currency' of international medical communication, in all specialties, in terms of diagnosis (7), a major effort was made to assign an ICD code to every referral at the time of presentation. This did not prove a difficult task, and it was felt that the codes given, as defined in operational form in the ICD Pocket Guide (8), fully did justice to the range of cases presented (Table 1). Hereafter ICD codes will be cited, for convenience.

' $F$ ' codes cover 'Mental and Behavioural Disorders' (chapter V in ICD-10). The only other code, ' $\mathrm{X}$ ', covers 'Intentional selfharm' (chapter XX in ICD-10). Adjustment reaction (F43) was sub-divided into either mostly Theatre-related (t), or mostly Home-

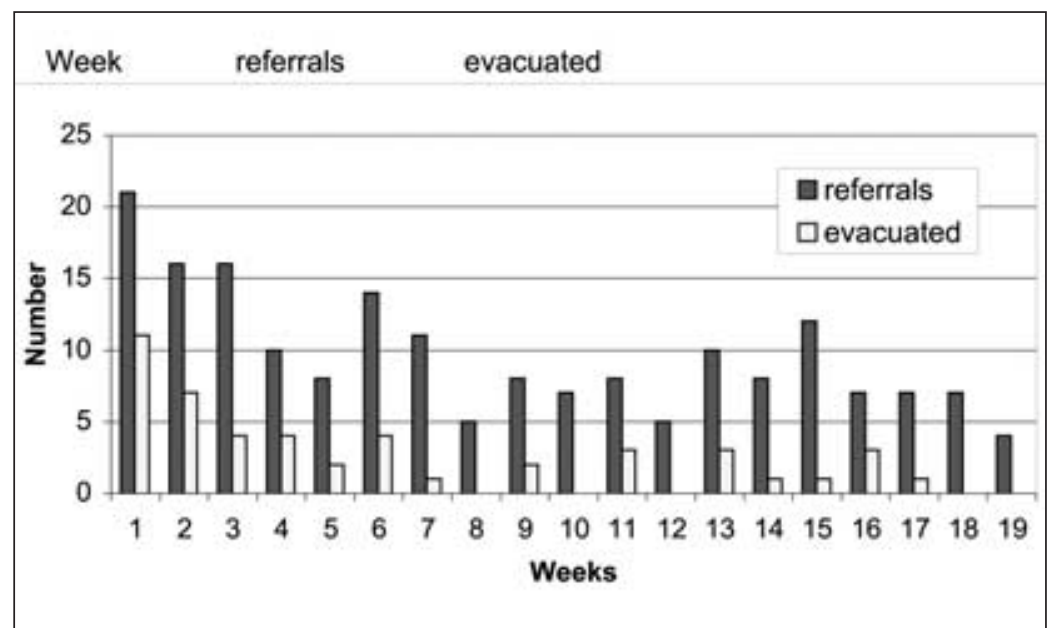

Fig 1. Number of psychiatric referrals and evac's per week over the 19 week study period, from 17 March (day 1) to 23 fuly (day 129) 2003. related $(\mathrm{h})$. These suffixes, $\mathrm{t}$ or $\mathrm{h}$, were added to the F43 code accordingly; hence F43(h) or F43(t).

\section{Results}

The total number of cases seen was 170 . Twelve cases were seen on two occasions, and one on three. So in all there were 184 referrals. The two outcomes here considered were firstly whether the person was fit to safely return to their unit in theatre ('RTU'); or secondly required evacuation on psychiatric grounds, usually to UK. Outcomes are presented by both rank and $\mathrm{TA} /$ regular status prior to mobilisation, for Coyote and Shaibah.

The diagnoses and outcomes for all psychiatric cases is shown in Table 1. As noted, the commonest diagnosis (68\%) was Adjustment reaction (F43), mostly theatrerelated $(45 \%)$ or mostly home-related $(23 \%)$. Theatre-related events predominated in a ratio of 2:1. Only seven of the 116 cases of Adjustment reaction were evacuated, ie $94 \%$ were RTU. Of those evacuated, four were seen by day 3 , and all by day 45 . Referrals where the diagnosis was Depressive disorder $(\mathrm{F} 32, \mathrm{n}=23)$ or Intentional selfharm (sharp object, X78, $\mathrm{n}=7$ ) were all evacuated. The eight cases of somatoform disorder (F45) were all RTU. Delirium (F05) was seen in two cases, both due to heat exhaustion, and both RTU.

Overall $123(72 \%)$ of the 170 cases seen were RTU, and $47(28 \%)$ were evacuated. However, the number of referrals, and evacs, per week was greatest in weeks 1 to 3 (Figure 1). Thereafter, the number of referrals averaged 8 per week and ranged from four to 
Table 2. Outcome of psychiatric assessment according to rank.

\begin{tabular}{|l|c|c|c|c|}
\hline Rank & $\begin{array}{c}\text { Total No. } \\
\text { Cases }\end{array}$ & $\begin{array}{c}\text { Total No. } \\
\text { Referrals }\end{array}$ & \multicolumn{2}{|c|}{$\begin{array}{c}\text { No. (\%) based on } \\
\text { Total No. Referrals }\end{array}$} \\
\hline OR & & & RTU* & Evac $^{\star \star}$ \\
\hline NCO & 142 & 154 & $115(75)$ & $39(25)$ \\
\hline Officer & 14 & 16 & $15(94)$ & $1(6)$ \\
\hline TOTAL & 14 & 14 & $7(50)$ & $7(50)$ \\
\hline
\end{tabular}

${ }^{\star} R T U=$ Returned to Unit in theatre

${ }^{\star}{ }^{\star}$ Evac $=$ Evacuated home, usually to UK

A case is one individual; Referrals include cases seen on more than one occasion

Table 3. Outcome of all psychiatric cases based on final referral according to Rank and whether Regular or TA.

\begin{tabular}{|c|c|c|c|c|}
\hline \multirow[t]{2}{*}{ Rank } & \multirow[t]{2}{*}{ Regular or TA } & \multirow[t]{2}{*}{ Total No. } & \multicolumn{2}{|c|}{ No. (\%) based on final referral } \\
\hline & & & RTU* & Evac $^{\star \star}$ \\
\hline \multirow[t]{3}{*}{ All Ranks } & Regular & 110 & $78(71)$ & $32(29)$ \\
\hline & TA & 60 & $45(75)$ & $15(25)$ \\
\hline & TOTAL & 170 & $123(72)$ & $47(28)$ \\
\hline \multirow[t]{3}{*}{ OR } & Regular & 101 & $70(69)$ & $31(31)$ \\
\hline & TA & 41 & $33(80)$ & $8(20)$ \\
\hline & TOTAL & 142 & $103(73)$ & $39(27)$ \\
\hline \multirow[t]{3}{*}{$\mathrm{NCO}$} & Regular & 8 & 7 (87.5) & $1(12.5)$ \\
\hline & TA & 6 & $6(100)$ & $0(0)$ \\
\hline & TOTAL & 14 & $13(93)$ & $1(7)$ \\
\hline \multirow[t]{3}{*}{ Officer } & Regular & 1 & $1(100)$ & $0(0)$ \\
\hline & TA & 13 & $6(46)$ & $7(54)$ \\
\hline & TOTAL & 14 & $7(50)$ & $7(50)$ \\
\hline
\end{tabular}

${ }^{\star} R T U=$ Returned to Unit in theatre

${ }^{\star}{ }^{\star}$ Evac $=$ Evacuated home, usually to UK

fourteen. In the first 3 weeks there were 53 referrals, of which 31 (58\%) were RTU and $22(42 \%)$ were evacuated. After week 3, evacs per week ranged from 0 to 4 , average 1.6 , and evac rate was $19 \%$.

- Of the 12 cases seen on two occasions, diagnosis given on the first referral in all was Adjustment reaction (nine F43t, three F43h). Seven were evacuated on the second occasion, three then being F32, two X78, and two F41.1. The other five remained F43; three F43t, two F43h.

- The case presenting on three occasions was RTU on each. Diagnosis given on each was F43t.

- One case presented originally as 'bullying'. Investigations were initiated, but the person presented again 12 days later with profound depression and required evacuation. Whether the second presentation was caused by the first, or was already in place in rudimentary form then, was not resolved in theatre. Diagnosis was F43t on the first referral; F32 on the second.
- A self-styled 'Conscientious Objector' was referred, to ensure that no psychiatric disorder was present, presumably before due legal process ensued. Diagnosis given was F43t, and the case was RTU.

The majority of cases seen were Other Ranks (ORs), reflecting their numbers in theatre (Table 2). Only 14 NCOs and 14 officers were referred.

A full breakdown of outcome based on final referral according to rank and whether Regular or TA prior to mobilisation is presented in Table 3. The outcome was similar for Regular and TA. Thirteen out of 14 officer referrals were TA before mobilisation, and evacs were highest in this group.

The influence of gender on other outcome measures was investigated (Table 4). There were no significant differences (Fisher's Exact Test) between the sexes as to whether the referral was Regular or TA prior to mobilisation, and whether the outcome was Evac or RTU. Significantly more female officers were referred compared to male officers (Fisher's Exact Test, $\mathrm{P}<0.001$ ). 
Table 4. Influence of gender on referrals according to Rank, Regular or TA and whether RTU or Evac.

\begin{tabular}{|l|l|c|c|}
\hline & & Male (\%) & Female (\%) \\
\hline \multirow{2}{*}{ Total } & & 146 & 24 \\
\hline \multirow{4}{*}{ Rank } & OR & $125(86)$ & $17(71)$ \\
\cline { 2 - 4 } & NCO & $14(10)$ & $0(0)$ \\
\cline { 2 - 4 } & Officer & $7(5)$ & $7(29)$ \\
\hline \multirow{4}{*}{ Service } & Regular & $97(66)$ & $13(54)$ \\
\cline { 2 - 4 } & TA & $49(34)$ & $11(46)$ \\
\cline { 2 - 4 } & RTU & $107(73)$ & $16(66)$ \\
\cline { 2 - 4 } & EVAC & $39(27)$ & $8(33)$ \\
\hline
\end{tabular}

${ }^{\star} P<0.001$, Fisher's Exact Test

\section{Discussion}

In a clinical context, and relating to individual referred personnel in various stages of despair and need, FMHT staff found that certain themes recurred, which were not reflected, nor capable of so being, in data presented. These are portrayed below, correlated with data as far as possible.

Peak referral rate was in the first three weeks (Figure 1). This was the time of both opening hostilities, with the outcome of the War as yet uncertain, and also the early 'settling-in' period, when supportive social bonds had yet to be fully established. Some personnel are very dependent upon the group support provided by friends whom they have known and with whom they have trained, and react badly when used to 'backfill' vacancies in strange units on their own. At a time of great stress in itself, they are plunged into a new group environment, with its own cohesiveness and dynamics, knowing nobody. Confidence may be eroded, and they risk feeling under-valued and under-trained in their new location. It is suggested that the potential extra needs of Attached personnel should be borne in mind, and treated with care, both by donor and receiving units, in order to protect their skill-base and self-confidence. Where possible two or more from the same unit should be attached together, rather than just one.

In an ideal world GP records would be available to MOs on recruitment. In eight known cases previous mental health problems were undeclared on mobilisation. However, perhaps a person's resolve to try to 'start afresh' should be respected. There is a 'right to self-determination' with regard to treatment compliance. In the light of this, folk should be asked to consider the extra stresses they can expect to experience in theatre, and not choose just then to stop medication (eg antidepressants) they might happen to be on, but rather to ensure that they have adequate supplies. Such a decision at such a critical and vulnerable time may seem odd and counter-intuitive. But it happened. As one person said, as they recalled their pre-mobilisation rush, "I was swept-up with all the euphoria..."

Although heat always added to discomfort, heat exhaustion as such was not a significant problem in psychiatric referrals in Coyote. Firstly such cases were managed in the general wards; secondly water was widely on supply, and it seemed that advice to maintain regular fluid intake was generally respected and followed at this stage; and finally, in early May seriously hot summer conditions still lay ahead. Heat-related problems impinged later, well after the end of offensive operations, and began to be seen in Shaibah. Psychiatric aspects of Heat-related Illness is the subject of a separate study.

As noted above, welfare and pastoral care was considered to be of the utmost importance; to enhance home contacts, provide spiritual and moral support, and try to 'normalise' the person's psychological reaction state, and re-direct concerns into non-psychiatric areas of resolution wherever possible. It was felt that a better, and earlier, knowledge of other relevant local sources of expertise in theatre would have been beneficial, and should be acquired as soon as possible through early personal contact and introduction. This would be with other embedded $\mathrm{CMH}$ personnel, and also padres and welfare. Getting to know, and developing trust in, individuals is at least as important as a 'paper' knowledge of the resource, with relaxed liaison thereafter as necessary, and as the chaos of war permits.

Adjustment disorder was the commonest presentation, and probably many factors contribute to this. Firstly, this was a highlyselected group, with the likelihood of those with serious mental illness being filtered-out long before. The fact that only one possible case of serious mental illness emerged (hypomanic episode, F30) bears this out. Secondly, the morale-enhancing effect of a known deployment end-date is not to be under-rated. This became known only gradually to medical units in Op Telic I, over half-way through what for most was a 6month tour. Uncertainty in this respect was 
an often-cited source of added distress and frustration, at all levels. But once end-date was known, the individual invariably felt more in control and better contented, with a time in mind for which to 'aim'.

It is reasonable to question the robustness and accuracy of clinical decisions made in theatre. RTU decisions would seem to be supported by the low number of second referrals within the period of study. Whether any were re-referred afterwards, could probably be determined. As to those evacuated, this data is available, and might be the subject of a further study.

Three main tasks emerged with regard to the FMHT role: psychiatric triage and treatment; psychological support of hospital staff; welfare and pastoral care liaison. Firstly, psychiatric triage and treatment comprised the practical application of the 'Treatment Philosophy' depicted above, with 'Results' as described. Secondly, psychological support of hospital staff comprised three aspects; educative, which lay in suggesting, on request, ways for ward nursing staff to deal with psychological distress in their physically ill patients, whether arising in cases of massive disfiguring injury, or where psychological factors comprised a temporary barrier to recovery; restorative, wherein ward staff were helped to deal with their own stress and doubts, in the course of work tasks which were liable to be often taxing and sometimes morally ambiguous; and 'de-briefing', the adverse effect of which was fully known and appreciated (6). A model was in place to provide this on request, following a major incident, with minimal psychological focus. Instead the emphasis was on event reconstruction and narrative, resolving of misunderstanding, completing knowledge gaps, and enhancing team cohesion. This was requested and provided only once, as noted above, on 24 June (day 100). Thirdly, relating to welfare and pastoral care liaison, close links were maintained with the Defence Medical Welfare Service, and the Padres' dept. Some individuals' requirements were, or became, essentially welfare in nature. For example, a need to make specific contact with folk at home to share information, allay fears, or ensure family needs were being met. Padre involvement was robustly encouraged as appropriate, both to provide immediate spiritual and moral support, and also to ensure a future such link thereafter, whatever the outcome, whether evacuation home, or return to unit in theatre. Every possible opportunity was thus taken to 'normalise' the person's psychological reaction state, and redirect concerns into non-psychiatric areas of resolution.

\section{Conclusion}

The psychiatric management model used here is built upon previous military medical doctrine $(3,4)$, and contains no radically new features. The treatment philosophy was mostly discovered and determined by FMHT staff at an early stage, although its articulation (1) was more retrospective. Around three quarters of all referrals were kept in theatre, all by RTU. As skill and confidence was gained, the RTU rate improved to over $80 \%$ after the first three weeks, so the overall result might have been better. Such 'learning from experience' is inevitable, and others might make use of ours. All this was in the context of excellent medical and surgical support, within the setting of a well-equipped and well-staffed field hospital. If it is agreed that RTU is the preferred outcome for a psychiatric referral, it needs to be shown that an alternative model to the present one improves upon the RTU rates here achieved. In the present theatre, there seemed little point in deploying FMHT staff in other locations. Wide promulgation of such psychiatric management is to be encouraged, especially given the numbers in theatre of nurses and other staff with some psychiatric training and experience. But the main, formal, psychiatric treatment effort is probably most efficiently focussed within the Field Hospital location.

\section{Acknowledgment}

Thanks to all 202 FMHT personnel.

\section{References}

1. Glass AJ. Psychotherapy in the Combat Zone. Am 7 Psy 1954;110:725-31; and, Principles of Combat Psychiatry. Milit Med 1955;117:27-33.

2. Shephard B. A War of Nerves, Soldiers and Psychiatrists 1914-1994. London Pimlico 2002.

3. Solomon Z, Benbenishty R. The role of proximity, immediacy, and expectancy in frontline treatment of combat stress reaction among Israelis in the Lebanon War. Am f Psy 1986; 143, 5: 613-17.

4. Salmon TW. The Care and Treatment of Mental Diseases and War Neuroses ('Shell Shock') in the British Army. NewYork: WarWork Committee of the National Committee for Mental Hygiene, 1917.

5. Data from presentations at DMS Tri-service Psychiatric conference, RDMC, Gosport, 25 September 2003

6. Wessely S, Rose S, Bisson J. A systematic review of brief psychological interventions ("debriefing") for the treatment of immediate trauma related symptoms and the prevention of post traumatic stress. In: Cochrane Review. Cochrane Library Issue 2. Oxford: Update Software, 1998.

7. Sartorious N, Kaelber CT. Progress towards achieving a common language in psychiatry: results from the field trials of the clinical guidelines accompanying the WHO Classification of Mental and Behavioural Disorders in ICD-10. Arch Gen Psy 1993;50:115-124.

8. Pocket Guide to the ICD-10 Classification of Mental and Behavioural Disorders. Churchill Livingstone 1994. 